\title{
Onchocerciasis in Ecuador: Changes in Prevalence of Ocular Lesions in Onchocerca volvulus Infected Individuals over the Period 1980-1990
}

\author{
Philip J Cooper, Roberto Proaño, Carlos Beltran, Mariela Anselmi, \\ Ronald H Guderian ${ }^{+}$
}

Onchocerciasis Control Programme, Hospital Vozandes, Casilla postal 17-17-691, Quito, Ecuador

Trends in prevalence rates of onchocercal ocular lesions were examined over the period 1980 to 1990 using data from two cross-sectional surveys. There was evidence for increasing prevalence of anterior chamber microfilariae, iridocyclitis, optic atrophy, and chorioretinopathy. Large increases in prevalence, in particular, were seen for posterior segment lesions: optic atrophy increased from $2.7 \%$ to $6.4 \%$ and chorioretinopathy from $8.8 \%$ to $35.6 \%$. Greatest increases in these lesions were seen in the Chachi which was attributed to the large increases in prevalence of microfilariae in the anterior chamber particularly in those aged 30 years or greater. The study findings suggest that ocular onchocerciasis is evolving in parallel with the well documented parasitological changes.

Key words: Ecuador - ocular infectious disease - filariasis

Onchocerciasis is a major blinding disease in the developing world. Up to 18 million people are estimated to be infected in Africa and Central and South America (WHO 1987). Of these, approximately one million are blind or suffer severe visual loss (Thylefors 1989).

Little is known about the natural history and progression of ocular onchocerciasis, particularly posterior segment lesions. Prospective longitudinal studies have been performed in defined communities in West Africa (Budden 1976, Anderson et al. 1976a, 1978, Rolland et al. 1978). These have stressed the importance of the presence of ocular microfilariae in the evolution of sight-threatening disease. Chemotherapeutic trials (Anderson et al. 1976b, c, Taylor et al. 1986, Rothova et al. 1990, Whitworth et al. 1991) and vector control programmes (Dadzie et al. 1990) have demonstrated an improvement or resolution of anterior segment lesions following the reduction of ocular microfilarial burdens, though posterior segment lesions remained unchanged (Anderson et al. 1976b, Taylor et al. 1986, Dadzie et al. 1990, Whitworth et al. 1991) or deteriorated (Anderson et al. 1976c, Rothova et al. 1990).

No comparable studies have been performed in the Americas. The evolution of ocular

\footnotetext{
The work was supported by Christoffel Blindenmission and the Onchocerciasis Project, Hospital Vozandes. PC was supported by a training award from the British Medical Research Council and a Sackler studentship.

${ }^{+}$Corresponding author. Fax: 593-2-447-263

Received 30 May 1995

Accepted 10 December 1995
}

onchocerciasis in the Esmeraldas focus in Ecuador is of particular interest in the light of the increases in infection prevalence and dermal microfilarial counts which have been documented over the period between 1980 and 1990 (Guderian et al. 1989, 1990, Guderian \& Shelley 1992). This report examines secular trends in prevalence rates of onchocercal ocular lesions over the same period to determine if ocular disease has remained static or evolved in parallel with these epidemiological changes.

\section{MATERIALS AND METHODS}

Study population - The study was performed in the hyperendemic area of the rain forest focus of onchocerciasis in the Santiago River Basin of Esmeraldas Province (Guderian et al. 1989). The communities living in this area included both indigenous Amerindian (Chachi tribe) and Black (of African descent) communities. The ethnographic features of these communities have been described elsewhere (Guderian et al. 1982).

Two cross-sectional studies were performed in 1980 and 1990 respectively. In 1980, an eye clinic was established for a two week period in San Miguel, Rio Cayapas, a community in the hyperendemic area. The presence of the clinic was advertised through community leaders and all patients who attended the clinic were examined and biopsied for the presence of dermal microfilariae. Those who were microfilariae-positive only were included in the analysis. No other exclusion criteria were used. In the 1990 study, the single criterion for inclusion was a previously documented positive skin snip and eligible patients were brought by canoe to a central examination centre for ocu- 
lar assessment. Both studies recruited individuals from the same communities, though not necessarily the same individuals. Data collection for both studies was performed by the same team and the same two ophthalmologists were employed.

Parasitological examination - Skin biopsies were taken from both iliac crests with a Stolz corneoscleral punch. The biopsies were weighed and placed in micro well plates in saline. The number of emergent microfilariae were counted after $24 \mathrm{hr}$. The geometric mean of the two snips was calculated for each person.

Ophthalmological examination - Uncorrected visual acuity was tested by illiterate $\mathrm{E}$ or literate Snellen charts at $6 \mathrm{~m}$ in broad daylight. If either acuity was $<6 / 12$, it was assessed with a pinhole. Slit-lamp examination was conducted after head down positioning of patients for 10 min using a Topcon slit-lamp. The following were noted: the presence of live and dead microfilariae in the anterior chamber and cornea, punctate opacities in the cornea, and sclerosing keratitis. Any other abnormality of the anterior chamber structures was recorded. After pupil dilatation with $1 \%$ tropicamide and $10 \%$ epinephrine, the ocular fundus was examined with a Keeler indirect ophthalmoscope. Abnormalities of the retina, choroid, and optic disc were noted.

Statistical analysis - A direct comparison was made of the proportion of subjects with specified ocular lesions in the two studies. Prevalence rates in the 1990 study were calculated by direct standardisation using the 1980 study population as standard and 1990 age, sex, and race stratified prevalence rates. Microfilarial intensities are geometric mean counts $(\mathrm{mf} / \mathrm{mg})$ calculated from biopsies taken from both iliac crests.

\section{RESULTS}

Comparison of study populations - A total of 903 patients were examined in 1980 of which 660 $(73.1 \%)$ had dermal microfilariae and were included in the comparative analysis. In 1990, a total of 785 skin-snip positive persons were examined. The sex, race, and age composition of the two groups are shown in Tables I and II.

Skin microfilarial intensities (MfS) - MfS were
TABLE I

Sex and race distribution of the two study populations

\begin{tabular}{lcc}
\hline Group & 1980 & 1990 \\
\hline Black & $313(47 \%)$ & $287(37 \%)$ \\
Chachi & $347(53 \%)$ & $498(63 \%)$ \\
Male & $451(68 \%)$ & $434(55 \%)$ \\
Female & $209(32 \%)$ & $351(45 \%)$ \\
\hline Total & $660(100 \%)$ & $785(100 \%)$ \\
\hline
\end{tabular}

greater in the 1990 study $(34.7 \mathrm{mf} / \mathrm{mg}$ vs. $25.1 \mathrm{mf} /$ $\mathrm{mg}$ ) (Table III). This was also true of both race groups. Below 40 years of age MfS levels in 1990 were greater in all age groups (Fig. 1). MfS counts peaked at 15-19 years of age in 1990 but did not decline significantly in the older age groups. In contrast MfS counts peaked much later in those aged 40 to 49 years in 1980 . This was followed by a sharp decline. The same pattern was seen in both races.

Punctate keratitis - This lesion decreased in prevalence over the observation period from $52.3 \%$ in 1980 to $38.2 \%$ in 1990 (Table IV). The greatest change was seen in Black females where prevalence decreased from $41.8 \%$ to $19.1 \%$ over the study period. This decrease was seen in all age groups. The same pattern was seen in both races.

Microfilariae in the anterior chamber (MfAC) - MfAC were detected more often in the 1990 study group (34.5\% vs. $26.2 \%$ ) (Table IV). The largest increases were seen in Chachis where prevalence increased from $29.7 \%$ in 1980 to $41.8 \%$ in 1990. In contrast, prevalence rates in Blacks were unchanged (22.4\% vs. $22.0 \%$ ). The increase in MfAC prevalence was seen in those aged between 30 and 49 years; prevalence rates did not differ in the other age groups (Fig. 2). Much of this was accounted for by large increases over the same age range in the Chachi.

Sclerosing keratitis - No patients with this lesion were seen in either study.

Iridocyclitis - The two studies used different definitions for this lesion: in 1980 cases with mild low-grade anterior uveitis with flare and cells were included while the 1990 study only included individuals with advanced disease (evidence of past

TABLE II

Distribution of the two study population

\begin{tabular}{lccccccc}
\hline Group & \multicolumn{7}{c}{ Age group } \\
\cline { 2 - 8 } & $0-9$ & $10-19$ & $20-29$ & $30-39$ & $40-49$ & $50+$ & Total \\
\hline \multirow{2}{*}{1980} & 26 & 141 & 138 & 106 & 127 & 122 & 660 \\
& $(3.9 \%)$ & $(21.4 \%)$ & $(20.9 \%)$ & $(16.1 \%)$ & $(19.2 \%)$ & $(18.5 \%)$ & $(100 \%)$ \\
1990 & 87 & 227 & 175 & 103 & 93 & 100 & 785 \\
& $(11.1 \%)$ & $(28.9 \%)$ & $(22.3 \%)$ & $(13.1 \%)$ & $(11.9 \%)$ & $(12.7 \%)$ & $(100 \%)$ \\
\hline
\end{tabular}


TABLE III

Comparison of dermal microfilarial intensities (MfS) between the two studies

\begin{tabular}{lcc}
\hline Group & \multicolumn{2}{c}{ Skin infection intensity $(\mathrm{mf} / \mathrm{mg})$} \\
\cline { 2 - 3 } & 1980 Study & 1990 Study \\
\hline Chachi & 26.1 & 37.0 \\
Black & 24.0 & 30.6 \\
\hline Total & 25.1 & 34.7 \\
\hline
\end{tabular}

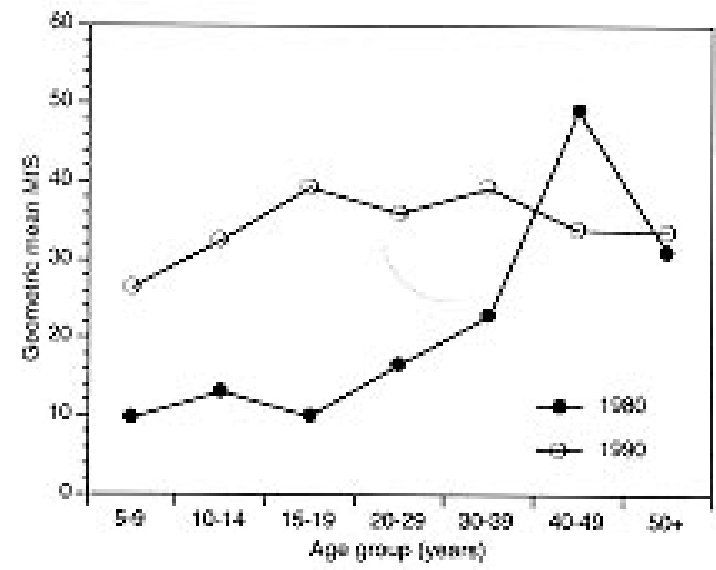

Fig 1: differences in skin microfilarial intensity (MfS) between the 1980 and 1990 studies by age.

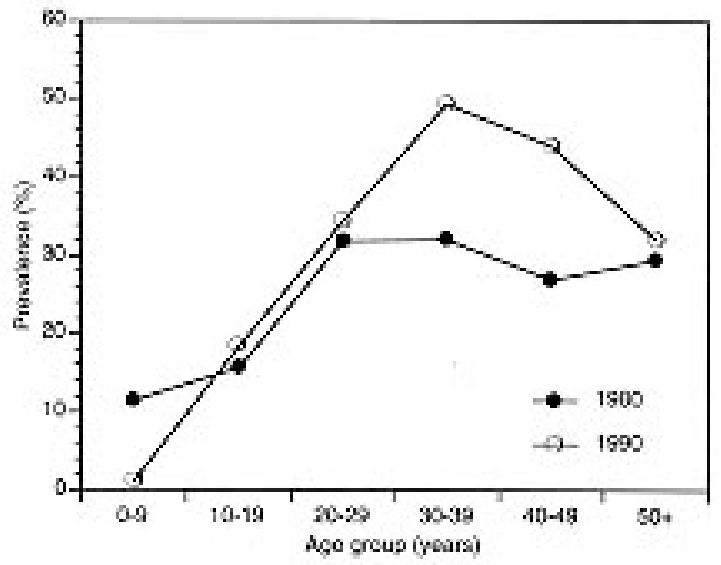

Fig. 2: prevalence of the finding of microfilarie in the anterior chamber (MfAC) according to age in 1980 and 1990.

iridial inflammation, development of pupillary distortion, pigment loss, and anterior and posterior synechiae). The prevalence of iridocyclitis remained unchanged over the 10-year period $(1.8 \%$ vs $2.2 \%$ ), but as this lesion was predominantly acute anterior uveitis in 1980 (advanced iridocyclitis was rare; only $3(25 \%)$ of the 12 affected had posterior or anterior synechiae while the remaining $9(75 \%)$ had flare and cells only), it is likely that a real increase in the prevalence of

TABLE IV

Prevalence rates $(\%)$ of onchocercal ocular lesions by race and sex in 1980 and 1990

\begin{tabular}{|c|c|c|c|c|c|}
\hline & PK & MfAC & IRID & $\mathrm{OA}$ & CHOR \\
\hline \multicolumn{6}{|l|}{1980} \\
\hline Black males & 55.9 & 22.2 & 1.7 & 6.4 & 12.0 \\
\hline Black females & 41.8 & 22.8 & 2.5 & 2.5 & 8.9 \\
\hline Black total & 52.4 & 22.4 & 1.9 & 5.4 & 11.2 \\
\hline Chachi males & 52.1 & 33.2 & 1.8 & 0.5 & 8.3 \\
\hline Chachi females & 52.3 & 23.8 & 1.5 & 0.0 & 3.8 \\
\hline Chachi total & 52.2 & 29.7 & 1.7 & 0.3 & 6.6 \\
\hline Male & 54.1 & 27.5 & 1.8 & 3.5 & 10.2 \\
\hline Female & 48.3 & 23.4 & 1.9 & 1.0 & 5.7 \\
\hline Total & 52.3 & 26.2 & 1.8 & 2.7 & 8.8 \\
\hline \multicolumn{6}{|l|}{1990} \\
\hline Black males & 42.8 & 26.4 & 4.6 & 13.4 & 33.7 \\
\hline Black females & 19.1 & 15.2 & 2.9 & 4.5 & 27.9 \\
\hline Black total & 33.5 & 22.0 & 3.8 & 10.0 & 31.4 \\
\hline Chachi males & 40.2 & 48.7 & 1.5 & 4.8 & 38.5 \\
\hline Chachi females & 42.2 & 34.4 & 0.7 & 3.6 & 41.8 \\
\hline Chachi total & 41.2 & 41.8 & 1.1 & 4.2 & 40.0 \\
\hline Male & 40.8 & 39.6 & 2.7 & 8.4 & 35.5 \\
\hline Female & 35.0 & 28.3 & 1.5 & 3.9 & 35.9 \\
\hline Total & 38.2 & 34.5 & 2.2 & 6.4 & 35.6 \\
\hline
\end{tabular}

1990 rates calculated by direct standardization using the age, sex, and race distribution of the 1980 population as standard. PK: punctate keratitis; MfAC: microfilariae in the anterior chamber; IRID: iridocyclitis; OA: optic atrophy; CHOR: chorioretinopathy. 
advanced iridocyclitis was seen in 1990 (0.5\% in 1980 vs $2.2 \%$ in 1990). A large increase in prevalence was seen in Black males (1.7\% vs $4.6 \%)$ and can be explained by large increases in prevalence in the oldest two age-groups.

Optic atrophy - The prevalence of this lesion increased in all race and sex groups (Table IV). Overall an increase from $2.7 \%$ to $6.4 \%$ was seen. This is largely accounted for by large increases in prevalence in those aged 40 years or greater (Fig. $3)$. The prevalence in the Chachi rose approximately fourteen-fold and doubled in Blacks (Table IV). This is largely accounted for by large increases in the two oldest age groups in Blacks and in all age groups in the Chachi.

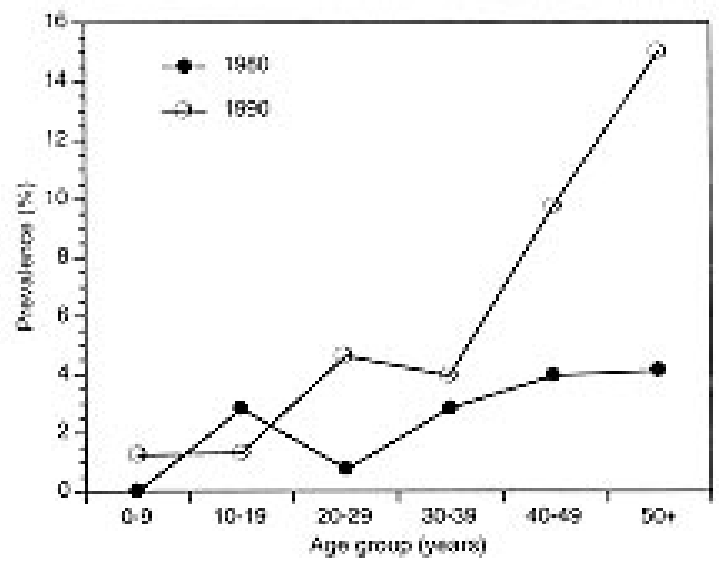

Fig. 3: prevalence of optic atrophy according to age in 1980 and 1990 .

Chorioretinopathy - The prevalence of chorioretinopathy increased dramatically between 1980 and 1990 from $8.8 \%$ to $35.6 \%$ (Table IV). Large increases were seen in all race and sex groups; the prevalence in Chachi females increased eleven-fold from $3.8 \%$ to $41.8 \%$. These increases were seen in all but the youngest age-group (Fig. 4). In the oldest age-group (50 years and older) prevalence increased from $22.1 \%$ in 1980 to $59.0 \%$ in 1990. The same pattern was seen when ageprevalence rates for this lesion were stratified by race. However, prevalence increases in Blacks were only apparent above 30 years of age.

\section{DISCUSSION}

The study findings can be generalized to those infected with Onchocerca volvulus living of the hyperendemic area, though they are likely to be an underestimate of the true effect as the selection bias in over-estimating ocular disease was much greater in the first than the second study. Selection into the 1980 study was based on the voluntary attendance of those complaining of ocular symptoms

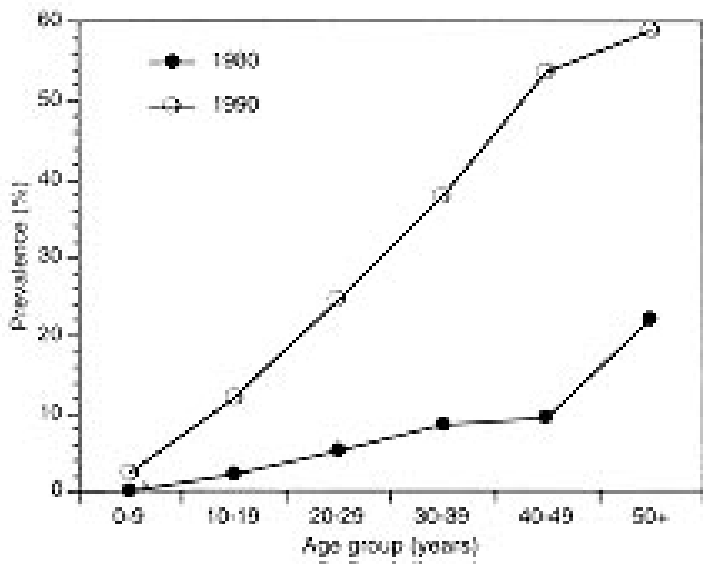

Fig. 4: prevalence of chorioretinopathy according to age in 1980 and 1990.

and as onchocerciasis was endemic in this area it is likely that most eye lesions seen were onchocercal in aetiology and those with more severe eye disease would have been more likely to attend. In contrast, selection into the 1990 study was performed by a health worker blind to ocular status using previously collated data. The potential for observer variation in the classification of ocular lesions bias was minimised by employing the same two ophthalmologists in both studies.

The same clinical pattern of ocular onchocerciasis was seen in both studies. This was characterized by mild anterior segment disease and a predominance of severe lesions in the posterior segment. Over the study period the prevalence of ocular lesions in the posterior segment increased dramatically. Increases were also seen in the prevalence of advanced iridocyclitis, though the prevalence of punctate keratitis diminished. The most plausible explanation for these epidemiological changes lies with the increased disease transmission which is likely to have occurred over the same period. There is substantial evidence that both prevalence and intensity of infection in the hyperendemic area has been increasing over the period 1980 to 1990 (Guderian et al. 1989, 1990, Guderian \& Shelley 1992). Over the period 1980 to 1986 , the prevalence of infection in the hyperendemic area increased from $63.9 \%$ to $93.7 \%$ in the Chachi and from $62.3 \%$ to $78.8 \%$ in Blacks and the intensity increased from 26.3 to $43.8 \mathrm{mf} /$ $\mathrm{mg}$ in both racial groups (Guderian et al. 1989).

The increased infection intensity would have resulted in a more rapid and heavier parasitisation of the eye (Budden 1957) resulting in an increase in the speed of evolution as well as prevalence of ocular lesions. The increased infection intensity resulted in an upwards shift of the age-intensity graph (Fig. 1) and an earlier peak (at 15-19 years 
in 1990 compared to 40-49 years in 1980). Peak infection intensities are seen at an earlier age in hyperendemic areas than in mesoendemic or hypoendemic areas (Duke \& Moore 1968, Dogba \& Tekou Komi 1994). One can speculate that the peaks of the age-intensity graphs of MfAC and $\mathrm{MfC}$ were also shifted to younger age groups by these increases in MfS. This would have also resulted in the observed increase in the rate of ocular parasitisation (MfAC) $(29.7 \%$ in 1980 vs $41.8 \%$ in 1990), though this was only evident in the Chachi. A number of longitudinal studies have demonstrated the importance of the presence of MfAC which is strongly associated with development of severe ocular lesions (namely sclerosing keratitis, iridocyclitis, optic atrophy, and chorioretinopathy (Budden 1957, 1976, Rolland 1974, Anderson et al. 1976, Rolland et al. 1978). The increased MfAC prevalence seen in the Chachi may explain why the prevalence of posterior segment lesions rose most dramatically in the Chachi (Table IV).

The increased rate of ocular parasitisation may have led to the decrease in the prevalence of punctate keratitis seen in this analysis. Marked punctate keratitis is mainly seen in early or light infections (Budden 1962, Choyce 1966, Anderson et al. 1974) and are often absent or scanty in heavily infected individuals. As punctate opacities are cellular reactions to dead microfilariae (Rodger 1960), the relative absence of these lesions in the more heavily infected may reflect the suppression of cellular responses associated with this disease (Maizels \& Lawrence 1991). An alternative explanation for the apparent decrease in the prevalence of punctate keratitis could be improved diagnostic precision.

The major difference between this study and previous longitudinal studies (Budden 1957, 1976, Rolland 1974, Anderson et al. 1976a, Rolland et al. 1978) is that other studies have been able to follow up the same individuals and thus have been able to document changes in pathology over time at an individual level. However, most of these studies have been small with sample sizes of 80 (9 years) (Rolland et al. 1978), 113 (6 years) (Rolland 1974), 69 (3.5 years) (Budden 1957) and 118 (1415 years) (Budden 1976). The largest study followed up 1,016 patients for four years (Anderson et al. 1976a). All these studies demonstrated significant increases in ocular morbidity over the study periods and in all these studies the evolution of severe ocular lesions and blindness was strongly associated with MfAC and the presence of ocular lesions (except MfC and punctate opacities) at the first examination. All these studies were, however, performed in highly endemic areas and progression to severe lesions occurred across specified age- bands (e.g. greater than ten years) in those who, with passing time during the study period, were becoming vulnerable to developing those lesions. In none of these studies was there convincing evidence for changes in prevalence rates of ocular lesions in the general infected population or of changing endemicity of infection. This important difference differentiates these West African studies, in which the disease is, more or less, in a state of equilibrium, from this study in which the disease is continuing to evolve.

\section{REFERENCES}

Anderson J, Fuglsang H, Hamilton PJS, Marshall TF de C 1974. Studies on onchocerciasis in the United Cameroon Republic. 11. Comparison of onchocerciasis in rain-forest and sudan-savanna. Trans $R$ Soc Trop Med Hyg 68: 209-222.

Anderson J, Fuglsang H, Marshall TF de C 1976a. Studies on onchocerciasis in the United Cameroon Republic. 111. A four year follow-up of 6 rain-forest and 6 savanna villages. Trans $R$ Soc Trop Med Hyg 70: 362-373.

Anderson J, Fuglsang H, Marshall TF de C 1976b. Effects of diethylcarbamazine on ocular onchocerciasis. Tropenmed Parasit 27: 263-278.

Anderson J, Fuglsang H, Marshall TF de C 1976c. Effects of suramin on ocular onchocerciasis. Tropenmed Parasit 27: 279-296.

Anderson J, Fuglsang H, Marshall TF de C, Radolowicz A, Vaughan JP 1978 Studies on onchocerciasis in the United Cameroon Republic. IV. A four-year follow-up of six rain-forest and six savanna villages. The incidence of ocular lesions. Trans $R$ Soc Trop Med Hyg 72: 513-515.

Budden FH 1957. Natural history of onchocerciasis. Brit J Ophthalmol 41: 214-227.

Budden FH 1976. The natural history of ocular onchocerciasis over a period of $14-15$ years and the effect on this of a single course of suramin therapy. Trans $R$ Soc Trop Med Hyg 70: 484-491.

Choyce DP 1966. Onchocerciasis: Ophthalmic aspects. Trans $R$ Soc Trop Med Hyg 60: 720-734.

Dadzie KY, Remme J, De Sole G 1990. Epidemiological impact of vector control 11. Changes in ocular onchocerciasis. Acta Leidensa 59: 127-139.

Dogba K, Tekou Komi B 1994. Contribution a l'evaluation de l'endemie onchocercquienne dans la prefecture de l'Amou (Togo). Bull Soc Path Exot 87: 110-111.

Duke BOL, Moore PJ 1968. The contributions of different age groups to the transmission of onchocerciasis in a Cameroon forest village. Trans $R$ Soc Trop Med Hyg 62: 22-28.

Guderian RH, Leon LA, Leon R, Corral F, Vasconez C, Johnston TS 1982. Report on a focus of onchocerciasis of Esmeraldas province of Ecuador. Am J Trop Med Hyg 31: 270-274.

Guderian RH, Beck BJ, Proaño SR, Mackenzie CD 1989. Onchocerciasis in Ecuador, 1980-1986: Epidemiological evaluation of the disease in the Esmeraldas Province. Eur J Epidemiol 5: 294-302.

Guderian RH, Beck BJ, Proaño SR 1990. Onchocerciasis 
in Ecuador: infection in children in the Santiago Basin focus, Province of Esmeraldas. Trans $R$ Soc Trop Med Hyg 84: 109-112.

Guderian RH, Shelley AJ 1992. Onchocerciasis in Ecuador: The situation in 1989. Mem Inst Oswaldo Cruz 87: 405-415.

Maizels RM, Lawrence RA 1991. Immunological tolerance: the key feature in human filariasis? Parasitol Today 7: 271-276.

Rodger FC 1960. The pathogenesis and pathology of ocular onchocerciasis. IV. The Pathology. Am J Ophthalmol 49: 560-594.

Rolland A 1974. Resultats de deux examens oculaires pratiques a 6 ans d'intervalle dans deux villageoise onchocerquiens de Haute-Volta. Bull Organ Mond Sante 51: 257-261.

Rolland A, Thylefors B, Pairault C 1978. Evolution sur 9 ans de l'onchocercose oculaire dans une communaute villageoise d'Afrique occidentale. Bull Organ Mond Sante 56: 805-810.
Rothova A, Van der Lelij A, Stilma JS, KlaassenBroekema N, Wilson WR, Barbe RF 1990. Ocular involvement in patients with onchocerciasis after repeated treatment with ivermectin. Am J Ophthalmol 110: 6-16.

Taylor HR, Murphy RP, Newland HS, White AT, D'Anna SA, Keyvan-Larijani E, Aziz MA, Cupp EW, Greene BM 1986. Treatment of onchocerciasis. The ocular effects of ivermectin and diethylcarbamazine. Arch Ophthalmol 104: 863-870.

Thylefors B 1989. Onchocerciasis. Community Eye Health 3: 5-6.

Whitworth JAG, Gilbert CE, Mabey DM, Maude GH, Morgan D, Taylor DW 1991. Effects of repeated doses of ivermectin in ocular onchocerciasis: community-based trial in Sierra Leone. Lancet 338: 1100-1103.

WHO 1987. World Health Organization Expert Committee on Onchocerciasis, third report. Technical Report Series 752, Geneva. 